\title{
Analysis of GLRA1 in hereditary and sporadic hyperekplexia: a novel mutation in a family cosegregating for hyperekplexia and spastic paraparesis
}

Frances V Elmslie, Simon M Hutchings, Valerie Spencer, Ann Curtis, Thanos Covanis, R Mark Gardiner, Michele Rees

Department of College London Medical School, The Rayne Institute, 5 University Street, London WC1E 6JJ, UK F V Elmslie

$S M$ Hutchings

R M Gardiner

M Rees

Department of Human Genetics, University of Newcastle upon Tyne, 19/20 Claremont Place, Newcastle upon Tyne NE2 4AA, UK

V Spencer

A Curtis

\section{Department of} Neurologyl

Neurophysiology, Aghia Sophia Children's Hospital, Athens 11527, Greece

T Covanis

Correspondence to:

Dr Rees.

Received 11 October 1995. Revised version accepted for publication 16 January 1996. Paediatrics, University

\begin{abstract}
Hyperekplexia is a rare condition characterised by the presence of neonatal hypertonia and an exaggerated startle response. Mutations have been described in GLRA1, the gene encoding the $\alpha 1$ subunit of the glycine receptor, in dominant families with hyperekplexia and in a single sporadic case, thought to represent an autosomal recessive form of the disease. In this study the coding region of the GLRA1 was analysed in eight probands with hyperekplexia by restriction digest and sequencing. Two familial cases were found to possess the previously described G1192A (R271Q) mutation in exon 6. In an additional family in which hyperekplexia cosegregates with spastic paraparesis, a novel $A$ to $G$ transversion at nucleotide 1206 in exon 6 was detected that changes a lysine at amino acid 276 to a glutamate (K276E). In four sporadic cases no mutations were found. In addition, one familial case did not have a mutation in the coding region of the gene.
\end{abstract}

( $f$ Med Genet 1996;33:435-436)

Key words: hyperekplexia; glycine receptor; GLRA1.

Table 1 Previously reported GLRA1 mutations in hyperekplexia

\begin{tabular}{lllll}
\hline Exon & Base change & Amino acid substitution & Mode of inheritance & Reference \\
\hline 6 & G1192A & Arg271Glu & Dominant & $2,3,4$ \\
6 & G1192T & Arg271Leu & Dominant & 2 \\
7 & A1216G & Tyr279Cys & Dominant & 3 \\
6 & T1112A & Ile244Asn & Recessive & 4 \\
\hline
\end{tabular}

Table 2 Sequencing primers used in the analysis of GLRA1

\begin{tabular}{|c|c|c|}
\hline Primer & $\begin{array}{l}\text { cDNA } \\
\text { Nucleotide No (22) }\end{array}$ & Sequence $\left(5^{\prime}-3^{\prime}\right)$ \\
\hline $\begin{array}{l}\text { Exon } 1-\mathrm{F} \\
\text { Exon } 1-\mathrm{R} \\
\text { Exon } 2-\mathrm{F} \\
\text { Exon } 2-\mathrm{R} \\
\text { Exon } 3-\mathrm{F} \\
\text { Exon } 3-\mathrm{R} \\
\text { Exon } 4-\mathrm{F} \\
\text { Exon } 4-\mathrm{R} \\
\text { Exon } 5 \mathrm{~A}-\mathrm{F} \\
\text { Exon } 5 \mathrm{~A}-\mathrm{R} \\
\text { Exon } 5 \mathrm{~B}-\mathrm{F} \\
\text { Exon } 5 \mathrm{~B}-\mathrm{R} \\
\text { Exon } 6-\mathrm{F} \\
\text { Exon } 6-\mathrm{R} \\
\text { Exon } 7-\mathrm{F} \\
\text { Exon } 7-\mathrm{R} \\
\text { Exon } 8-\mathrm{F} \\
\text { Exon } 8-\mathrm{R}\end{array}$ & $\begin{array}{l}62-78 \\
281-264 \\
382-400 \\
470-453 \\
486-503 \\
537-520 \\
559-576 \\
762-744 \\
781-800 \\
\text { Intronic } \\
\text { Intronic } \\
983-965 \\
1131-1150 \\
1203-1187 \\
1209-1222 \\
1341-1323 \\
1424-1443 \\
1495-1477\end{array}$ & $\begin{array}{l}\text { GCAGGTCTGGACGCTCTC } \\
\text { 'TGCTTTGTAGTCCACGAG } \\
\text { GCTCGCTCCGCACCAAGC } \\
\text { GGGCCTGATCCTGGCATC } \\
\text { CCAGTGAACGTGAGCTGC } \\
\text { CAGCAATGGACCAAAGC } \\
\text { TCAACATCTTCCTGCGGC } \\
\text { AGAGGACATTCCCATTCC } \\
\text { TGACACTGGCCTGCCCCATG } \\
\text { GATTTCTGCCTATCCCATGG } \\
\text { TGCTTCTGAGTGGTGACTG } \\
\text { GTGCTTGGTGCAGTATCTC } \\
\text { GCGGCAGATGGGTACTACC } \\
\text { GCAGAGATGGCTCGAGAG } \\
\text { GTGTCCTATGTGAAAGCCATTG } \\
\text { GCTTCCTCCTGAATCGGAG } \\
\text { CAAGGATGGCATCTCAGTCA } \\
\text { GACTTAAGATGGTGCAGGAG }\end{array}$ \\
\hline
\end{tabular}

$F=$ forward, $R=$ reverse.
Hyperekplexia or startle disease is characterised by the presence of an exaggerated startle response to unexpected auditory, visual, or sensory stimuli. Affected subjects frequently present at birth with hypertonia. Hyperekplexia is usually inherited in an autosomal dominant manner. Linkage studies localised the gene to distal chromosome 5q. ${ }^{1}$ Subsequently, mutations were detected in exon 6 of the gene encoding the $\alpha_{1}$ subunit of the glycine receptor, GLRA1. ${ }^{2}$ The previously described mutations are listed in table 1. All occur in large dominant pedigrees $^{2-5}$ except for one which may represent a recessive form of the disease. ${ }^{5}$ In this study, GLRA1 was analysed in eight probands with hyperekplexia. In three cases the families clearly display dominant inheritance; four cases are sporadic. In one family (family $R$ ) the family history is uncertain and it is possible that they may represent an autosomal recessive form of the disease. The pedigrees of the patients under investigation are shown in the figure. In the case of family $\mathrm{N}$, lower limb spasticity was found to cosegregate with the hyperekplexia trait $^{7}$ and is linked to markers in the GLRA1 region on chromosome 5 .

DNA was extracted from each proband and their relatives and intronic oligonucleotide primers flanking all exons of the GLRA1 gene ${ }^{23}$ were used to amplify individual exons from each proband. Exon 6 PCR products from all probands were investigated for the presence of the most common mutations at nucleotide position 1192 by restriction digestion with $X h o I$. $G$ to $A$ and $G$ to $T$ mutations at this position abolish an $X$ hoI restriction site. Probands G and $M$ were heterozygous for this site. Sequence analysis of exon 6 in both cases showed them to be heterozygous for a $G$ to $A$ base transition resulting in an arginine to glutamate amino acid change. Restriction fragment analysis of exon 6 PCR products from all available family members showed that these mutations segregated completely with the disease trait (data not shown).

Exon 6 PCR products from probands not possessing the 1192 mutation were subjected to sequence analysis (sequencing primers shown in table 2) using paramagnetic bead technology and the Applied Biosystems Prism single stranded sequencing kit. A heterozygous $A$ to $G$ base transition was detected at nucleotide 1206 in family $\mathrm{N}$ predicted to cause a Lys276Glu amino acid change in the mature 
Family R

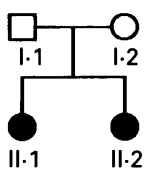

Family $T$

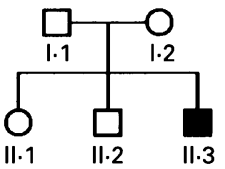

Family K

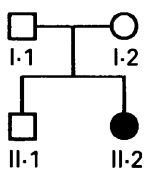

Family $\mathrm{N}$

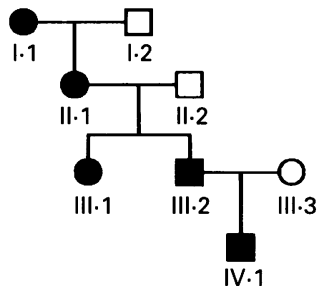

Family M

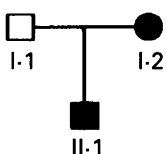

Family $\mathrm{H}$

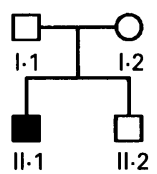

Family D

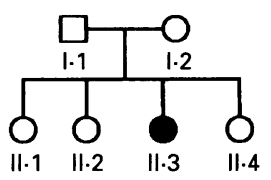

II.2

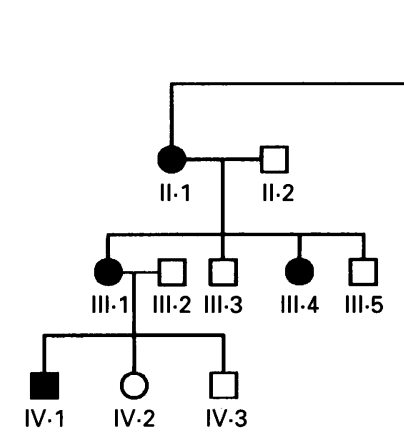

Family G

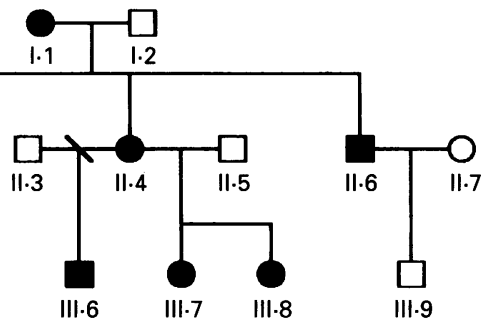

III.9

Hyperekplexia pedigrees. Closed symbols indicate affected members and open symbols unaffected subjects. In family $N$ the hyperekplexia trait cosegregates with spastic paraparesis.

protein. This change results in the loss of a StyI restriction site and was shown to segregate consistently with the hyperekplexia/spastic paraparesis trait in this family (data not shown). This mutation was not observed in any of the other families investigated and in addition was not observed in 100 normal chromosomes. PCR products from all other exons were sequenced in all affected subjects; no further mutations were detected.

We have therefore detected mutations in GLRA1 in three out of eight probands with hyperekplexia, all of whom originate from families in which there is a clear autosomal dominant pattern of inheritance. It is possible that the remaining five cases could represent new dominant mutations, or an alternative, autosomal recessive form of the disease as has been suggested previously. ${ }^{5}$

The finding of a mutation in GLRA1 in a family in which hyperekplexia cosegregates with lower limb spasticity raises the possibility that other related phenotypes may be attributable to mutations in GLRA1. Autosomal dominant pure hereditary spastic paraparesis is known to display genetic heterogeneity and there are families in which the trait appears unlinked to any of the three mapped loci on chromosomes 14,2 , or $15 .^{8-11}$ GLRA1 may therefore represent a candidate gene for these unlinked families.

\section{Note added in proof}

A further mutation in exon 6 of GLRA1 which changes a glutamine to a histidine at position 266 has recently been described in a dominant Italian family. ${ }^{12}$
We would like to thank all the clinicians who referred patients: Dr Peter Baxter who referred family N, Dr L Dubowitz, Dr R Davidson, Dr G McEnery, Dr J Wilson, and Professor A Harding. We are indebted to Drs $R$ Shiang, $S$ Ryan, and $J$ Wasmuth for their help and enthusiastic support. We would like to thank all the families who participated so willingly. $\mathrm{Dr}$ FV Elmslie is an Action Research Training Fellow.

1 Ryan SG, Sherman SL, Terry JC, Sparkes RS, Cristina Torres M, Mackey RW. Startle disease, or hyperekplexia: response to clonazepam and assignment of the gene (STHE) to chromosome 5q by linkage analysis. Ann Neurol 1992;31:663-8.

2 Shiang R, Ryan SG, Ya-Zhen Z, Hahn AF, O'Connell P, Wasmuth JJ. Mutations in the $\alpha 1$ subunit of the inhibitory glycine receptor cause the dominant neurological disorder, hyperekplexia. Nature Genet 1993;5:351-7.

3 Shiang R, Ryan SG, Zhu Y-Z, et al. Mutational analysis of familial and sporadic hyperekplexia. Ann Neurol 1995;38: $85-91$.

4 Schorderet DF, Pescia G, Bernasconi A, Regli F. An additional family with startle disease and a G1192A mutation at the $\alpha 1$ subunit of the inhibitory glycine receptor gene. Hum Mol Genet 1994;3:1201.

5 Rees MI, Andrew M, Jawad S, Owen NJ. Evidence for recessive as well as dominant forms of startle disease (hyperekplexia) caused by mutations in the $\alpha 1$ subunit of the inhibitory glycine receptor. Hum Mol Genet 1994;3: the inhibito.

6 Dubowitz LMS, Bouza H, Hird MF, Jaeken J. Low cerebrospinal fluid concentration of free gamma aminobutyric acid in startle disease. Lancet 1992;340:80-1.

7 Baxter P, Connolly S, Curtis A, et al. Codominant inheritance of hyperekplexia and spastic paraparesis. Dev Med Child Neurol (in press).

8 Hazan J, Lamy C, Melki J, Munnich A, de Recondo J, Weissenbach J. Autosomal dominant familial spastic paraplegia is genetically heterogeneous and one locus maps to chromosome 14q. Nature Genet 1993;5:163-7.

9 Hazan J, Fontaine B, Bruyn RPM, et al. Linkage of a new locus for autosomal dominant spastic paraplegia to new locus for autosomal dominant spastic paraplegi

10 Hentati A, Pericak-Vance MA, Lennon F, et al. Linkage of a locus for autosomal dominant familial spastic paraplegia to chromosome 2p markers. Hum Mol Genet 1994;3: 1867-71.

11 Fink JK, Wu CTB, Jones SM, et al. Autosomal dominant familial spastic paraplegia: tight linkage to chromosome 15q. Am f Hum Genet 1995;56:188-92.

12 Milani N, Dalpra L, Del Prete A, Zanini R, Larizza L. A novel mutation (Gln266 $\rightarrow$ His) in the alphal subunit of novel mutation (Gln $266 \rightarrow$ His) in the alphal subunit of hyperekplexia. Am f Hum Genet 1995;58:420-2. 